\title{
TOMOGRAFI KOMPUTER TRANSLASI ROTASI DENGAN MENGGUNAKAN METODE SAMPLING POLA SQUARE
}

\author{
Nur Kholis \\ Jurusan Teknik Elektro Fakultas Teknik UNMUH Ponorogo \\ J1. Budi Utomo no.10 Ponorogo \\ e-mail : kholis2as@yahoo.com
}

\begin{abstract}
Abstrak
Tomografi Komputer Translasi Rotasi merupakan peralatan medis yang digunakan untuk mengidentifikasi internal organ tubuh. Pengambilan sampel dilakukan secara translasi rotasi. Metode sampling pola square adalah metode yang digunakan dalam proses scanning pada obyek uji sehingga didapatkan data sampel dalam $\pi$ radian.Besarnya gerakan translasi $\Delta X r$ sama dengan gerakan rotasi $\Delta \phi r(\Delta X r=\Delta \phi r)$. Proses scanning menggunakan image sixe 31 piksel $x 31$ piksel. Hasil scanning diproyeksi menghasilkan sinogram dan direkonstruksi dihasilkan citra. Hasil dapat dilihat secara numeris dan visual dan hasilnya sama seperti obyek uji semula.dengan rata-rata e$\max 0.9729 \%$.
\end{abstract}

Kata kunci : scanning, rekonstruksi, piksel.

\section{A. PENDAHULUAN}

Sistem Tomografi komputer mengalami perkembangan yang sangat pesat, baik pada sistem maupun penggunaannya baik dalam bidang medis dan industri. Dalam penerapannya pada bidang material, system Tomografi komputer tersebut digunakan untuk mengamati struktur internal pada suatu bahan atau obyek yang akan diamati. Dalam bidang medis, system tersebut juga digunakan untuk mengamati organ internal yang ada dalam tubuh manusia.

Pada dasarnya sistem Tomografi komputer menyangkut distribusi serapan radiasi oleh suatu bahan. Dengan adanya distribusi serapan radiasi oleh bahan, proses dalam sistem Tomografi komputer dapat menghasilkan citra internal dari suatu obyek tanpa harus merusak bahan obyek itu sendiri. Dalam Penelitian ini diharapkan mempunyai hasil yang berupa citra, sehingga dengan citra tersebut dapat dilihat dengan jelas bahwa obyek akan sama seperti bentuk semula. Dalam pengambilan data pada system Tomografi komputer ini dilakukan secara translasi dan rotasi, agar hasil dapat dilihat dengan jelas.

\section{B. TUJUAN PENELITIAN}

Dalam penelitian ini mempunyai tujuan yaitu menerapkan dan mengembangkan sistem tomografi komputer secara transalasi-rotasi dengan menggunakan metode pola square yang hasil akhirnya diharapkan menghasilkan citra. 


\section{TINJAUAN PUSTAKA}

\section{Sistem Tomografi Komputer}

Aplikasi tomografi pertama kali diwujudkan oleh Base Well (1956) ketika dia merekomendasi peta emisi gelombang pendek yang dipancarkan matahari serangkaian dari serangkaian data radioastronomi. Sedangkan untuk aplikasi dalam bidang biologi, telah digunakan pada mikroskop elektron untuk merekonstruksi biomolekul kompleks dari serangkaian data transmisi mikrogram pada berbagai sudut. Metode tersebut dikembangkan oleh De Roisier (1968), Gordon, Bonder dan Herman (1970), Gilbert (1972), Smith, Peter dan Bates (1973).

Cormack dan Hounsfidd adalah dua orang yang dianggap mampu mewujudkan teknik tomografi komputer dalam dunia kedokteran. Berkat perannya dalam mengembangkan tomografi komputer, keduanya memperoleh Hadiah Nobel pada tahun 1979.(Morgan, CL.;1980)

Setelah tomografi komputer sinar-x terbukti dapat diwujudkan, teknik ini berkembang pesat. Berbagai sumber radiasi selain sinar-x, misalnya sinar-gamma, neutron, positron, bahkan gejala resonan magnetik inti (NMR) dan impedansi listrik yang digunakan. Berbagai istilah baru dalam tomografi komputer berkembang diantaranya CT Scan (Computerized Tomography), SPECT (Single Photon Emission Computerized Tomography), Tomografi Neutron, PET (Photon Emission Tomography), NMI (Nuclear Magnetic Imaging) dan EIT (Electrical Impedance Tomography).

Pada gambar 2 dilukiskan skema dasar sistem tomografi komputer generasi pertama, generasi kedua, generasi ketiga, generasi kempat dan generasi bentuk spiral. Perbedaan pada tingkat generasi didasarkan pada jumlah dan desain detector yang terlibat dan mekanisme translasi-rotasi ketiga proses akuisisi datanya.

Sistem tomografi komputer generasi pertama menggunakan sebuah detector dan sebuah sumber sinar-x dengan berkas pensil yang terkolimasi sangat tajam. Sistem tomografi ini sring disebut dengan sitem tomografi komputer translasi-rotasi, karena untuk memperoleh data proyeksi yang lengkap, sumber dan detector harus gerakkan secara translasi-rotasi.

Pada generasi kedua, detector yang digunakan tidak lagi tunggal, melainkan beberapa detector yang disusun berderet. Juga berkas sinar-x tidak lagi paralel seperti pada generasi pertama melainkan berupa berkas kipas dengan sudut kipas yang kecil walaupun gerakkan nya dilakukan sama dengan generasi pertama, namun prose dapat lebih singkat.

Sistem tomografi komputer generasi ketiga menggunakan sumber sinar-X dengan berkas kipas bersudut lebar dengan banyak detector yang tersusun berderet linear segaris atau melengkung membentuk kurva. Berkas sinar-x yang lebar melingkupi objek secara keseluruhan. Karena itu pada sistem ini, sumber dan detector praktis hanya bergerak secara rotasi tanpa perlu gerakan translasi. 


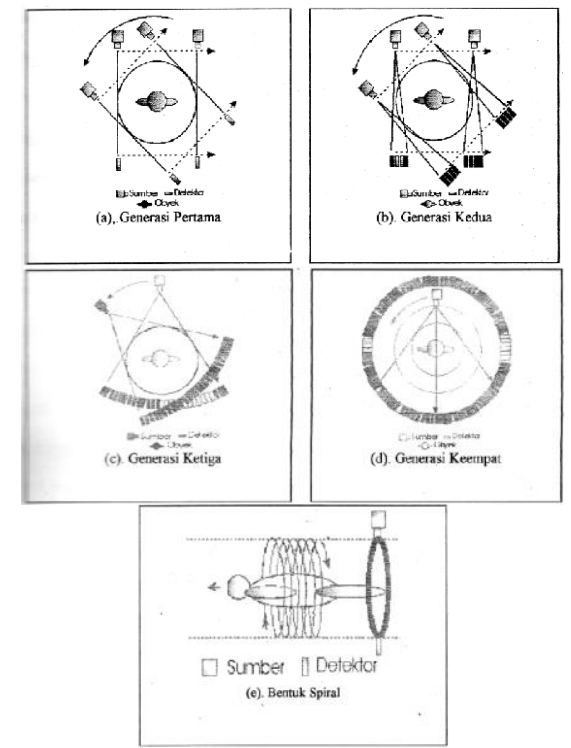

Gambar 1. Sistem Tomografi Pertama

(a) Generasi pertama, (b) Generasi kedua, (c) Generasi ketiga, (d) Generasi keempat dan (e) Generasi bentuk spiral.(Ain Kh., 2003)

Pada sistem tomografi komputer generasi keempat digunakan sumber sinar$\mathrm{x}$ dengan berkas kipas yang lebar dengan detektor yang tersusun secara penuh dalam bentuk lingkaran. Sumber sinar-x bergerak melingkar secara kontinyu sedangkan detektor diam.

Sistem ini selanjutnya dikembangkan menjadi sistem tomografi komputer generasi lanjut dengan menggunakan gererator berkas elektron dan target cicncin anoda serta aplikasi grakan spiral. Dengan prinsip ini, tidak ada gerakan, selain perubahan arah tembakan elektron kepada target anode penghasil sinar-X.

\section{Prinsip Kerja Sistem}

Sistem tomografi secara komputer generasi pertama merupakan suatu sistem secara komputer yang paling sederhana. Sistem ini menggunakan satu sumber radiasi dan satu detektor. Sumber radiasi dan detektor diletakkan segaris kemudian digerakkan secara translasi dan rotasi sehingga dihasilkan informasi data serapan radiasi pada obyek secara lengkap. Proses penyinaran pada sistem tomografi secara komputer generasi pertama dapat dilukiskan seperti pada gambar 2.(Avinash C.Kak, 1999)

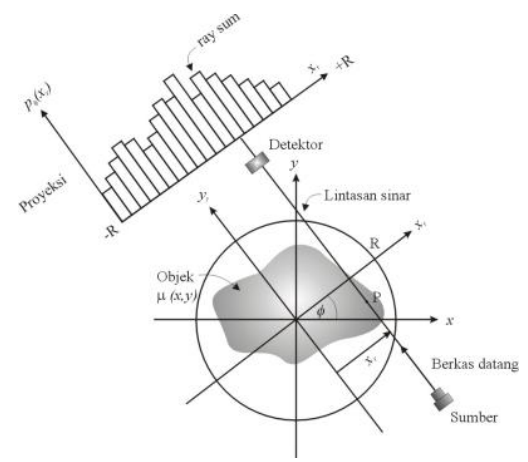

Gambar 2. Susunan sistem tomografi secara komputer. (Avinash C.Kak; 1999) 
Pada posisi yang sejajar sumbu $y$, sumber radiasi dan detektor secara bersama-sama bergerak translasi sepanjang daerah sumbu $x$, yaitu dari kedudukan $-R$ sampai dengan $R$, dimana $R$ menyatakan radius lingkaran obyek. Sepanjang gerak translasi pengambilan data dilakukan dengan lebar langkah $\Delta x$. Intensitas yang ditangkap detektor pada setiap kedudukan sumber-detektor disebut raysum. Kumpulan raysum sepanjang gerak translasinya disebut sebagai data proyeksi, yang diperoleh sepanjang pada daerah penyinaran dari suatu arah sudut pandang tertentu.

Setiap selesai satu gerak translasi, posisi sumber-detektor diputar terhadap sumbu koordinat $x-y$, dengan langkah rotasi $\Delta \varphi$ dari kedudukan mulai sudut 0 sampai dengan $\pi$ radian. Pada kekudukan sudut dari $\pi$ sampai dengan $2 \pi$ radian akan dihasilkan data yang sama dengan data pada sudut 0 sampai dengan $\pi$ radian. Jadi, pengambilan data pada arah rotasi cukup mulai sudut 0 sampai dengan $\pi$ radian.

Setelah diperoleh data proyeksi suatu obyek dari seluruh proses pemayaran, data proyeksi tersebut direkonstruksi untuk menghasilkan citra. Proses rekonstruksi menggunakan bantuan perangkat komputer yang berisi program rekontruksi $C T$ Imager.

\section{METODOLOGI PENELITIAN}

Penyinaran tunggal dari suatu obyek pada langkah translasi $x_{r}$, untuk kedudukan rotasi $\varphi$ menghasilkan ray-sum yang diberi notasi $P_{\varphi}\left(x_{r}\right)$. Apabila intensitas radiasi yang dikenakan pada obyek adalah $I_{0}$, maka dalam bahan radiasi, intensitas tersebut mengalami pelemahan secara eksponensial setelah melewati lintasan $L_{\varphi}\left(x_{r}\right)$. Intensitas radiasi yang ditangkap detektor adalah $I_{L}$, maka intensitas setelah melewati obyek dituliskan dalam bentuk persamaan (1.1):

$$
I_{L}=I_{0} \exp \left(-\int_{L_{\varphi}\left(x_{r}\right)} \mu(x, y) d s\right)
$$

dengan $\mu(x, y)$ menyatakan nilai koefisien pelemahan linier bahan pada koordinat $x$ $y$ sepanjang garis lintasan berkas radiasi $L_{\varphi}\left(x_{r}\right)$. Ray-sum pada sudut pandang $\varphi$ untuk kedudukan $x_{r}$ didefinisikan sebagai

$$
P_{\varphi}\left(x_{r}\right)=\ln \left(\frac{I_{0}}{I_{L}}\right)=\int_{L \varphi\left(x_{r}\right)} \mu(x, y) d s
$$

Jika seluruh ray-sum direpresentasikan dalam ruang koordinat $\left(x_{\mathrm{r}}, \varphi\right)$ atau ruang Radon (Suparta, GB., 2000). Jadi sinogram merupakan hasil transformasi obyek dari ruang kartesian ke ruang radon. 


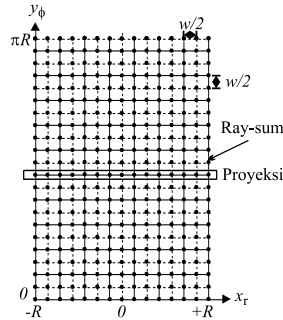

Gambar 3. Representasi proyeksi obyek dalam ruang radon (Avinash C. Kak., 1999)

Jumlah ray-sum yang terdapat dalam satu proyeksi pada suatu sudut pandang, ditentukan oleh radius daerah pemayaran $R$, dan panjang langkah pencuplikan $\Delta x$, dengan hubungan

$$
N=\frac{2 R}{\Delta x}
$$

dengan $N$ adalah jumlah ray-sum pada setiap data-proyeksi

Jumlah data-proyeksi dari seluruh proses penyinaran sepanjang sudut rotasi $\pi$ radian, terkait dengan besarnya langkah rotasi $\Delta \varphi$ dengan persamaan seperti berikut

$$
M=\frac{\pi}{\Delta \varphi}
$$

dengan $M$ menyatakan jumlah data-proyeksi yang diperoleh selama penyinaran.

Untuk memperoleh sinogram yang paling mendekati obyek yang ditransformasikan, nilai $N$ dan $M$ pada persamaan (1.3) dan (1.4) tidak dapat dipilih sembarang, karena resolusi dari citra yang dihasilkan antara lain bergantung pada langkah translasi-rotasi, dan lebar berkas radiasi yang terkolimasi.

Hubungan antara lebar langkah translasi dengan lebar berkas radiasi terkolimasi dinyatakan dalam persamaan seperti berikut.

$$
\Delta x=\frac{w}{2}
$$

dengan $w$ menyatakan lebar berkas radiasi terkolimasi. Apabila besaran resolusi sudut didefinisikan sebagai $\Delta y_{\varphi}=R \Delta \varphi$, dengan menggunakan cuplikan model grid, berlaku hubungan langkah translasi dan rotasi seperti berikut

$$
\Delta y_{\varphi}=\Delta x_{r}
$$

Dari persamaan (1.3), (1.4), dan (1.5) diperoleh

$$
M=\frac{\pi N}{2}
$$

Metode pengambilan data yang demikian itu disebut metode sampling pola square. 


\section{E. HASIL DAN PEMBAHASAN}

Hasil pengujian scanning pada obyek uji adalah berbentuk sinogram dengan menggunakan resolusi dengan image size 31 piksel x 31 piksel. Dalam hasil pengujian scanning ini menggunakan kolimator $5 \mathrm{~mm}$, karena hasil pengujian lebih baik dibandingkan dengan kolimator $1 \mathrm{~mm}$ dan $3 \mathrm{~mm}$. Hal tersebut diakibatkan karena energi radiasi yang ditangkap detektor $\mathrm{NaI}(\mathrm{Tl})$ habis. Hasil scanning obyek uji referensi dapat dilihat dalam gambar 4.

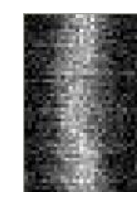

(a)

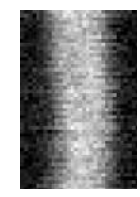

(b)

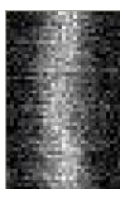

(c)

Gambar 4. Sinogram data scanning dari Obyek Uji, Obyek uji-1 (a), Obyek uji-2 (b) dan Obyek uji-3 (c).

Dari sinogram direkonstruksi akan menghasilkan citra. Hasil rekonstruksi dapat dilihat dalam gambar 5:

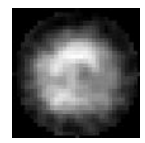

(a)

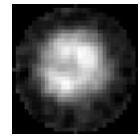

(b)

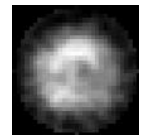

(c)

Gambar 5. Citra Rekonstruksi dari Sinogram Obyek Uji referensi, Obyek uiji-1 (a), Obyek uji-2 (b) dan Obyek uji-3 (c).

\section{F. ANALISIS HASIL PENELITIAN}

Dalam hasil pengujian scanning dan rekonstruksi mempunyai hasil yang berkualitas tinggi pada imadge size 31 piksel x 31 piksel. Hasil pengujian scanning dilakukan lima kali pengujian dengan obyek uji berbeda dan rekonstruksi menghasilkan citra. Hasil rekonstruksi dari lima obyek uji diperlihatkan dalam tabel berikut.

Tabel 1. Hasil Rekonstruksi Pada Obyek Uji-1

\begin{tabular}{|c|c|c|}
\hline File ke & $\begin{array}{c}\text { Rmsd } \\
(\%)\end{array}$ & $\begin{array}{c}\text { e_max } \\
(\%)\end{array}$ \\
\hline 1 & 0.0636 & 0.304 \\
\hline 2 & 0.0777 & 0.951 \\
\hline 3 & 0.0495 & 0.304 \\
\hline 4 & 0.0428 & 0.304 \\
\hline 5 & 0.0495 & 0.304 \\
\hline $\begin{array}{c}\text { Rata- } \\
\text { rata }\end{array}$ & 0.05562 & 0.9729 \\
\hline
\end{tabular}

Tabel 2. Hasil Rekonstruksi Pada Obyek Uji-2 


\begin{tabular}{|c|c|c|}
\hline File ke & $\begin{array}{c}\text { Rmsd } \\
(\%)\end{array}$ & $\begin{array}{c}\text { e_max } \\
(\%)\end{array}$ \\
\hline 1 & 0.0353 & 0.144 \\
\hline 2 & 0.0333 & 0.145 \\
\hline 3 & 0.0337 & 0.141 \\
\hline 4 & 0.0372 & 0.143 \\
\hline 5 & 0.0345 & 0.145 \\
\hline Rata-rata & 0.09477 & 0.1436 \\
\hline
\end{tabular}

Tabel 3. Hasil Rekonstruksi Pada Obyek Uji-3

\begin{tabular}{|c|c|c|}
\hline File ke & $\begin{array}{c}\text { Rmsd } \\
(\%)\end{array}$ & $\begin{array}{c}\text { e_max } \\
(\%)\end{array}$ \\
\hline 1 & 0.038 & 0.293 \\
\hline 2 & 0.0434 & 0.293 \\
\hline 3 & 0.0386 & 0.147 \\
\hline 4 & 0.0328 & 0.22 \\
\hline 5 & 0 & 0 \\
\hline Rata-rata & 0.03056 & 0.1906 \\
\hline
\end{tabular}

\section{G. KESIMPULAN}

Dalam penelitian ini didapatkan suatu kesimpulan sebagai berikut:

1. Pada proses scanning pada tomografi komputer dilakukan secara translasi dan rotasi atau konsep tersebut merupakan metode sampling pola square dengan metode tersebut besarnya gerakan translasi $\Delta X r$ sama dengan gerakan rotasi $\Delta \phi r(\Delta X r=\Delta \phi r)$, sehingga metode tersebut dapat digunakan sebagai metode penelitian ini.

2. Hasil rekonstruksi pada obyek uji dilakukan 5 kali pengujian dan didapatkan rata-rata e-max $0.9729 \%$, sehingga pada penelitian ini dapat dikatakan berhasil karena hasilnya mendekati $0 \%$.

\section{H. DAFTAR PUSTAKA}

Avinash C. Kak. (1999). Principle Of Computerized Tomographic imaging. IEEE Press.

Agfianto Eko Putra. (2002). Penapis Aktif Elektronika. Yogjakarta : C.V. Gava Media.

Ain, Kh. (2003). Fast Algebraic Reconstruction Method For Raysum Data Raysum Data Set Of Pixel Based Sampling, UGM Yogyakarta.

Bobbi Bennett. (2003). The Low-Down on Osteoporosis What We Know and What We Don't.

Brooks, R.A., and Chiro, D. (1976). Priciple of Computer Assisted Tomography (CAT) in Radiographyc and Radioisotopic Imagin., Phis.Med.Biol.,21(5). 
D. Protopopescu and J.C. Mc. George. (2004). Experiment Single Analyzer. Department Of Phisics and Astronomi.

Glenn F. Knoll. (1989). Radiation Detection And Measurement. second edition. Jhon Wiley \& Sons.

Gordon, R., (1974). A Tutorial on ART (Algebraic Reconstruction Techniques). IEEE Transactions on Nuclear Science, NS(21).

Herman, G.T. (1980). Imaging Reconstruction from Projecion: The Fundamentals of Computed Tomography. New York : Academic Press.

I. Fogelman, GM. Blake. (December 2000). Different Approach to Bone densitometry. The Journal of Nuclear Medicine, vol.41, No.12.

Kusminarto. (1998). Tinjauan Fisika dan Matematika Tomografi dan Perkembangannya. Jurnal Fisika Indonesia, 8(11).

Morgan, CL., and Phil, M. (1983). Basic Principle Of Computerized Tomograph. Baltimore : University Park Press.

Rinaldi Munir. (2004). Pengolahan Citra Digital dengan Pendekatan Algoritmik. Bandung : Penerbit Informatika Bandung.

SL. Follin, LMB. HANSEN. (2002). Prevention of Osteoporosis and Osteoporotic Fractur. Kentucky : Creative educational Concept Inc.

*) Penulis adalah Dosen Teknik Elektro FT. UNMUH Ponorogo, alumni Program Pascasarjana Teknik Elektro Bidang Keahlian Elektronika ITS Surabaya. 